\section{MAKING COMMUNITY SAFETY WORK FOR SCOTLAND}

E Lumsden Correspondence: Royal Society for the Prevention of Accidents, Livingstone House, 43 Discovery Terrace, Heriot-Watt University Research Park, Edinburgh EH14 4AP, UK

10.1136/ip.2010.029215.995

In 2007 the new nationalist Scottish Government delivered its first budget and 3-year spending plans and set out the terms of new relationship with local government. This 'Concordat' included a move to provide Single Outcome Agreements for each of the 32 local authorities, based on an agreed set of national outcomes. These outcomes include: that we live longer, healthier lives; that we live our lives safe from crime, disorder and danger and; that we have strong, resilient and supportive communities where people take responsibility for their own actions and how they affect others. The Scottish Community Safety Network (SCSN) has been working with its members over the last 3 years to re-align itself with the Concordat to make it a more effective organisation and has expanded its membership to engage more effectively with police forces, fire and rescue services, health organisations and others (such as RoSPA) involved with Community Safety Partnerships. It has also been working to be a more effective "strategic voice" for Community Safety in Scotland with a view to embedding community safety and partnership working to achieve a real change in behaviour and working practices within all community safety organisations. During 2009, the Network incorporated as a company limited by guarantee and was registered with the Office of the Scottish Charities Regulator (OSCR) as a
Scottish Charity. The Network is now governed by a Board of Directors (including Elizabeth Lumsden, Community Safety Manager, RoSPA) drawn from across the Community Safety Sector in Scotland. The Network has also been working on, among other things, standardised practice and intervention notes and an improved and recently launched website (www. safercommunitiesscotland.org). 